Article

\title{
Secondary Hemophagocytic Lymphohistiocytosis and Autoimmune Cytopenias: Case Description and Review of the Literature
}

\author{
Bruno Fattizzo $^{1,2, *(\mathbb{D})}$, Marta Ferraresi ${ }^{3,4}$, Juri Alessandro Giannotta ${ }^{1}$ (D) and Wilma Barcellini ${ }^{1}$ \\ 1 Oncohematology Unit, Fondazione IRCCS Ca' Granda Ospedale Maggiore Policlinico, 20122 Milan, Italy; \\ jurigiann@gmail.com (J.A.G.); wilma.barcellini@policlinico.mi.it (W.B.) \\ 2 Department of Oncology and Oncohematology, University of Milan, 20122 Milan, Italy \\ 3 Department of Internal Medicine, Fondazione IRCCS Ca' Granda Ospedale Maggiore Policlinico, \\ 20122 Milan, Italy; marta.ferraresi01@gmail.com \\ 4 Department of Internal Medicine, University of Milan, 20122 Milan, Italy \\ * Correspondence: bruno.fattizzo@unimi.it; Tel.: +39-02-55033477
}

Citation: Fattizzo, B.; Ferraresi, M.; Giannotta, J.A.; Barcellini, W. Secondary Hemophagocytic Lymphohistiocytosis and Autoimmune Cytopenias: Case Description and Review of the Literature. J. Clin. Med. 2021, 10, 870. https://doi.org/10.3390/jcm10040870

Academic Editor: Tamam Bakchoul

Received: 27 January 2021

Accepted: 15 February 2021

Published: 20 February 2021

Publisher's Note: MDPI stays neutral with regard to jurisdictional claims in published maps and institutional affiliations.

Copyright: (c) 2021 by the authors. Licensee MDPI, Basel, Switzerland. This article is an open access article distributed under the terms and conditions of the Creative Commons Attribution (CC BY) license (https:/ / creativecommons.org/licenses/by/ $4.0 /)$.

\begin{abstract}
Hemophagocytic lymphohistocytosis (HLH) is a rare hyperinflammatory condition which may be primary or secondary to many diseases, including hematologic malignancies. Due to its life-threatening evolution, a timely diagnosis is paramount but challenging, since it relies on nonspecific clinical and laboratory criteria. The latter are often altered in other diseases, including autoimmune cytopenias (AIC), which in turn can be secondary to infections, systemic autoimmune or lymphoproliferative disorders. In the present article, we describe two patients presenting at the emergency department with acute AICs subsequently diagnosed as HLH with underlying diffuse large B cell lymphoma. We discuss the diagnostic challenges in the differential diagnosis of acute cytopenias in the internal medicine setting, providing a literature review of secondary HLH and AIC.
\end{abstract}

Keywords: autoimmune hemolytic anemia; immune thrombocytopenia; hemophagocytic lymphohistiocytosis; diffuse large B cell lymphoma

\section{Introduction}

Hemophagocytic lymphohistocytosis (HLH) is a rare hyperinflammatory condition caused by over-activated and ineffective immune response [1]. HLH can be primary (familial, generally occurring in early childhood), or secondary to infections, autoimmune and autoinflammatory diseases, malignancies, and drugs [2]. The epidemiology of HLH varies greatly depending on the underlying condition. In hematological cancers, HLH incidence ranges from about $3 \%$ in lymphomas to $9 \%$ in acute myeloid leukemia. Of note, familial HLH, although rare, may also become evident in adulthood and should be ruled out [3]. HLH is a severe, life-threatening condition with high mortality rate ranging from $20 \%$ to $80 \%[1,2]$. Signs and symptoms of HLH reflect immune activation and hypercytokinemia [4] and include several unspecific clinical and laboratory findings, making the diagnosis a challenge for the treating physician. Likewise, autoimmune cytopenias (AIC), particularly autoimmune hemolytic anemia (AIHA) and immune thrombocytopenia (ITP), may be primary or secondary to various conditions including infections, systemic autoimmune diseases, and hematological malignancies that may require specific work-up and treatment [5-7]. The latter include non-Hodgkin lymphomas (NHL), a setting where the differential diagnosis of cytopenias may be particularly challenging. Here we describe two cases presenting to the emergency department with acute severe AICs subsequently diagnosed as HLH in the context of diffuse large B cell lymphoma (DLBCL) and provide a literature review of both conditions. 


\section{Patients and Methods}

The patients have been evaluated at our center. Clinical and laboratory data have been collected. The diagnosis of HLH was made according to the Histiocyte Society criteria (HLH-2004) [8]. HLH is diagnosed if at least 5 out of the following features are present: fever, splenomegaly, cytopenia, increased ferritin, decreased fibrinogen and/or elevated triglycerides, elevated soluble CD25, morphologic evidence of hemophagocytosis, and reduced or absent natural killer (NK) cytotoxicity. Cutoff values and additional features are shown in Table $1[1,9,10]$. AICs were diagnosed according to standard criteria [5]. Diagnosis of DLBCL has been made according to current practice by flow cytometry of bone marrow sample and/or lymph node biopsy. The study was conducted in accordance with the Helsinki declaration. A review of literature about secondary HLH and AIC was performed by searching for indexed articles and published abstracts until January 2021 in MEDLINE via PubMed and the National Library of Medicine.

Table 1. Hemophagocytic lymphohistocytosis (HLH)-2004 diagnostic criteria.

\begin{tabular}{|c|c|}
\hline Feature & Cut Off \\
\hline Fever & $\geq 38.5^{\circ} \mathrm{C}$ \\
\hline \multicolumn{2}{|l|}{ Splenomegaly } \\
\hline Cytopenias & $\geq 2$ cell lines \\
\hline -Hemoglobin * & $<9 \mathrm{~g} / \mathrm{dL}$ \\
\hline -Platelets * & $<100 \times 10^{9} / \mathrm{L}$ \\
\hline -Neutrophils * & $<1 \times 10^{9} / \mathrm{L}$ \\
\hline Hyperferritinemia & $>500 \mathrm{mcg} / \mathrm{L}$ \\
\hline $\begin{array}{l}\text { Hypofibrinogenemia or } \\
\text { hypertriglyceridemia }\end{array}$ & $\begin{array}{l}<150 \mathrm{mg} / \mathrm{dL} \\
>265 \mathrm{mg} / \mathrm{dL}\end{array}$ \\
\hline Elevated soluble CD25 & $>2400 \mathrm{U} / \mathrm{mL}$ \\
\hline Hemophagocytosis & Bone marrow, other tissues \\
\hline \multicolumn{2}{|c|}{ Reduced or absent NK cytotoxicity } \\
\hline \multicolumn{2}{|l|}{ Other features } \\
\hline \multicolumn{2}{|c|}{ Elevated transaminase and bilirubin } \\
\hline \multicolumn{2}{|l|}{ Elevated LDH } \\
\hline \multicolumn{2}{|l|}{ Elevated d-dimers } \\
\hline \multicolumn{2}{|c|}{ Cerebrospinal fluid pleocytosis and/or elevated protein } \\
\hline
\end{tabular}

\section{Results}

\subsection{Case \#1}

A 68-year-old female patient was admitted to the emergency room (ER) in June 2020 because of progressive dyspnea and fever. Her past medical history was positive for systemic lupus erythematosus/rheumatoid arthritis overlap and splenomegaly $(18 \mathrm{~cm})$. The autoimmune disease was not active at the time of presentation and family history for familial HLH was negative. Two weeks earlier the patient had been admitted to another hospital and diagnosed with warm AIHA (with direct antiglobulin test, DAT, positive with anti-IgG anti-sera). She had been treated with steroids with partial response and discharged with $\mathrm{Hb} 10.7 \mathrm{~g} / \mathrm{dL}$ on oral prednisone $25 \mathrm{mg}$. At presentation, the patient was febrile and critically ill, and laboratory tests (Table 2) showed severe pancytopenia and markedly altered hemolytic markers (particularly LDH) with inappropriately normal 
reticulocyte counts. Increased inflammatory markers and microbiology tests suggested a urinary tract infection and piperacillin-tazobactam was started, together with transfusions and i.v. methylprednisolone $1 \mathrm{mg} / \mathrm{kg} /$ day for warm AIHA. Subsequently, hemolytic anemia improved (Figure 1), whilst thrombocytopenia progressively worsened with the appearance of atypical lymphocytes and extreme elevation of ferritin. Further investigations excluded other causes of hemolysis (absence of schistocytes, normal ADAMTS13 levels, absence of paroxysmal nocturnal hemoglobinuria -PNH- clones) and confirmed DAT positivity. Tests for active infectious diseases were all negative. Steroid dose was increased (100 $\mathrm{mg} /$ day) and intravenous immunoglobulins (IvIg $0.4 \mathrm{~g} / \mathrm{kg} /$ day for 5 days) were administered. CT scan showed worsening splenomegaly $(22 \mathrm{~cm})$ and a retroperitoneal mass. PET scan displayed a diffusely increased uptake in spleen, bone marrow and lymph nodes, suggestive for lymphoproliferative disorder (Figure 2A). Flow cytometry on peripheral lymphocytes and bone marrow evaluation revealed massive localization of DLBCL. Severe thrombocytopenia persisted, along with a new elevation of LDH, ferritin (6530 mcg/L) and the appearance of hypertriglyceridemia $(806 \mathrm{mg} / \mathrm{dL}$, fasting). These findings, together with fever and increased splenomegaly, satisfied 5 out of 8 HLH-2004 criteria, suggesting the development of an HLH. Soon after, patient's clinical conditions rapidly deteriorated leading to death for multiple organ failure (MOF).

Table 2. Laboratory exams of Patient \#1.

\begin{tabular}{cccc}
\hline Laboratory Tests & Day $\mathbf{1}$ & Day 7 & Normal Ranges \\
\hline Hb (g/dL) & 6.5 & 8.9 & $13.5-17.5$ \\
PLT (10e9/L) & 22 & 12 & $130-400$ \\
WBC (10e9/L) & 3.9 & 14.7 & $4.8-10.8$ \\
Neutrophils (10e9/L) & 0.63 & 4.8 & $1.5-6.5$ \\
Lymphocytes (10e9/L) & 3.3 & 9.4 & $1.2-3.4$ \\
LDH (U/L) & 21759 & 1711 & $135-225$ \\
AST (U/L) & 927 & 424 & $8-48$ \\
ALT (U/L) & 101 & 43 & $9-59$ \\
GGT (U/L) & 61 & 116 & $8-61$ \\
ALP (U/L) & 95 & 137 & $40-129$ \\
Total bilirubin (mg/dL) & 1.99 & & $0.12-1.1$ \\
Unconjugated bilirubin (mg/dL) & 1.1 & & $0-0.8$ \\
Creatinine (mg/dL) & 1.6 & 1.48 & $0.72-1.18$ \\
PT ratio & 2.19 & 1.3 & $0.84-1.20$ \\
aPTT ratio & 1.27 & 0.78 & $0.86-1.2$ \\
CRP (mg/dL) & 4.28 & 1.33 & $<0.5$ \\
Procalcitonin (mcg/L) & 11.2 & 2.82 & $<0.05$ \\
Reticulocytes (10e12/L) & 0.022 & 0.097 & $0.02-0.10$ \\
Haptoglobin (mg/dL) & $<10$ & $<10$ & $30-200$ \\
Beta2-microglobulin (mg/L) & 15.2 & - & $<0.2$ \\
\hline
\end{tabular}

$\overline{\mathrm{Hb}}$, hemoglobin; PLT, platelet count; WBC, white blood cells; LDH, lactate dehydrogenase; AST, aspartate aminotransferase; ALT, alanine aminostransferase; GGT, gamma glutamyl transferase; ALP, alkaline phosphatase; $\mathrm{CRP}, \mathrm{C}$ reactive protein.

\subsection{Case \#2}

An 82-year-old man was admitted to a local hospital in June 2020 because of progressive shortness of breath and fever. Laboratory tests and a chest $\mathrm{CT}$ scan were suggestive for mild interstitial pneumonia (SARS-CoV-2 and pulmonary embolism excluded), and the patient was discharged on empiric antibiotic therapy. Seven days later, he presented to the ER of our hospital due to persistency of dyspnea and fever. Blood tests (Table 3) showed marked lymphopenia, moderate anemia with inadequate reticulocytosis, altered hemolytic markers and increased $C$ reactive protein $(C R P)$ and lactates $(2.5 \mathrm{mmol} / \mathrm{L})$. Chest $X$-ray and microbiologic workup (HBV, HCV, HIV, CMV, EBV, parvovirus B19, and Leishmania serology, and CMV, EBV, parvovirus B19, and mycobacteria nucleic acid tests) were negative and empiric levofloxacin was started. The CT scan showed severe splenomegaly $(17 \mathrm{~cm})$. Beta- 2 microglobulin and ferritin levels were increased, whilst further tests performed for 
hemolytic anemia and splenomegaly were all negative. Autoimmune screening, including DAT, was negative except for complement fractions 3 and 4 consumption and presence of crioagglutinins. Platelet counts progressively decreased (Figure 3) and anti-platelets antibodies were found positive. Bone marrow morphology was not diagnostic and trephine not evaluable. The PET scan showed diffusely increased uptake in bone marrow and spleen (Figure 2B). Intermediate dose prednisone was started ( $25 \mathrm{mg} /$ day) with transient resolution of fever and dyspnea. A few days later, platelet counts dropped and 5 criteria for HLH were satisfied (fever, bicytopenia, splenomegaly, hyperferritinemia, hypertriglyceridemia and hypofibrinogenemia) (Table 3). Dexamethasone $10 \mathrm{mg} / \mathrm{sqm}$ was instituted and bone marrow evaluation repeated, being diagnostic for DLBCL. Disseminated intravascular coagulation with MOF rapidly developed and the patient died.

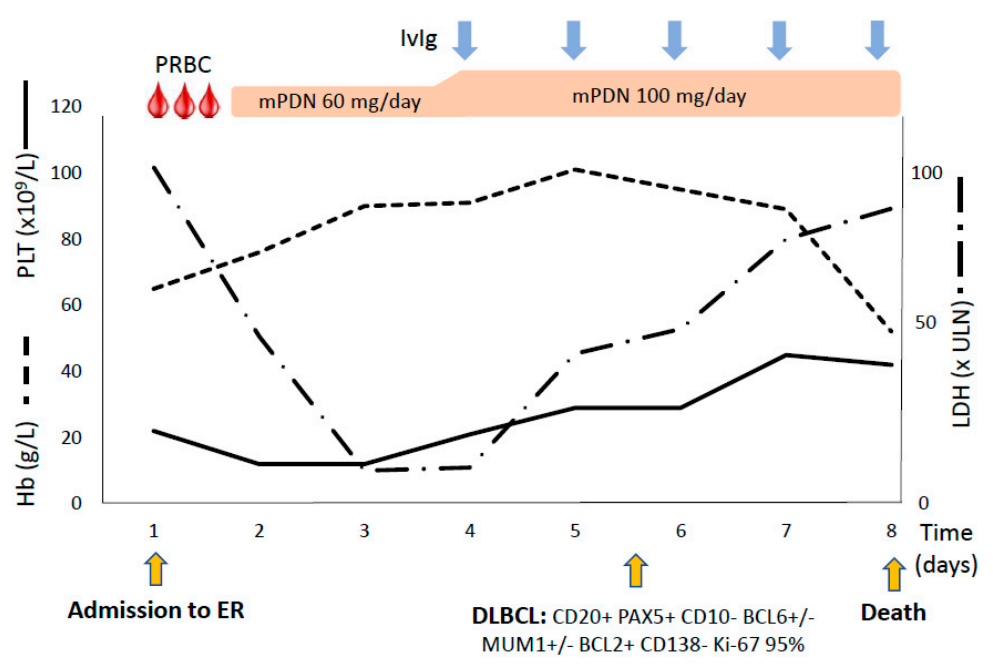

Figure 1. Clinical course of patient \#1. Trend of hematologic parameters and therapies administered. $\mathrm{Hb}$, hemoglobin; PLT, platelet count; $\mathrm{LDH}$, lactate dehydrogenase, expressed as times above the upper limit of normal (ULN); PRBC, packed red blood cell units; IvIg, intravenous immunoglobulins; mPDN, methylprednisolone; ER, emergency room; DLBCL, diffuse large B cell lymphoma with its immunophenotype.

A

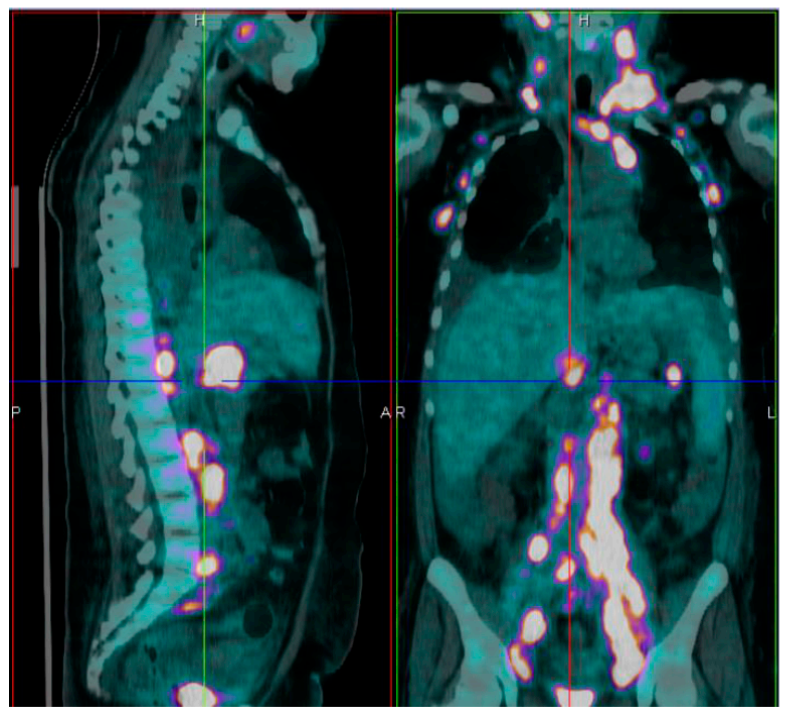

B

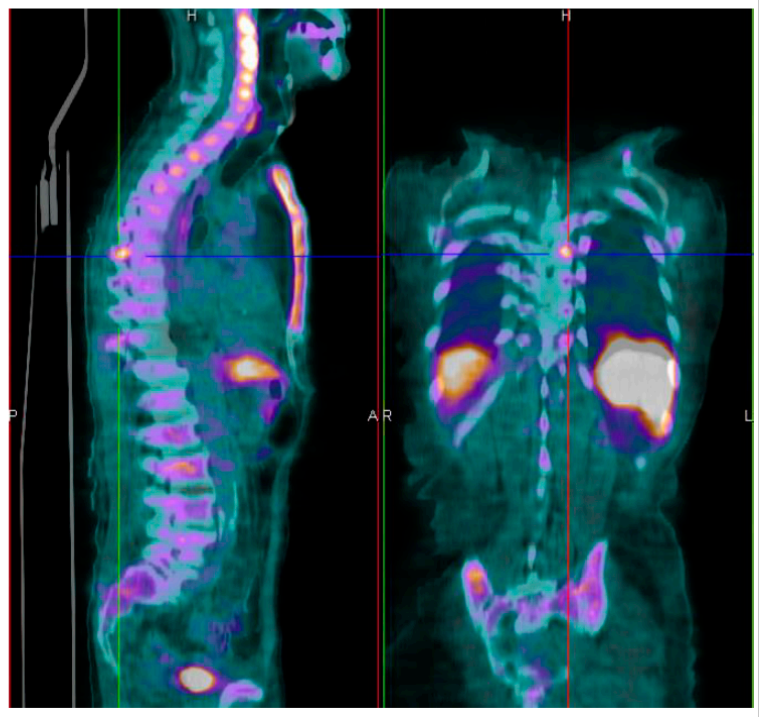

Figure 2. Positron emission tomography (PET) scan images of Patient \#1 (A, markedly increased uptake in lymph-nodes and retroperitoneum) and Patient \#2 (B, diffusely increased uptake in bone marrow and spleen). 
Table 3. Laboratory exams of Patient \#2.

\begin{tabular}{ccccc}
\hline Laboratory Tests & Admission & Week 3 & Week 6 & Normal Ranges \\
\hline Hb (g/dL) & 8.8 & 8.8 & 7.8 & $13.5-17.5$ \\
PLT (10e9/L) & 147 & 50 & 19 & $130-400$ \\
WBC (10e9/L) & 4.7 & 4.6 & 18.8 & $4.8-10.8$ \\
Neutrophils (10e9/L) & 3.0 & 2.9 & 14.8 & $1.5-6.5$ \\
Lymphocytes (10e9/L) & 0.3 & 0.26 & 2.1 & $1.2-3.4$ \\
Reticulocytes (10e12/L) & 0.107 & - & - & $0.02-0.1$ \\
LDH (U/L) & 742 & 734 & 1390 & $135-225$ \\
Total bilirubin (mg/dL) & 1.2 & 2.13 & 1.99 & $0.12-1.1$ \\
Unconjugated bilirubin (mg/dL) & 1.0 & 1.64 & 1.4 & $0-0.8$ \\
Haptoglobin (mg/dL) & 45 & - & 24 & $30-200$ \\
Beta2-microglobulin (mg/dL) & 5.0 & - & - & $<0.2$ \\
Creatinine (mg/dL) & 1.14 & 1.05 & 1.34 & $0.72-1.18$ \\
Ferritin (mcg/L) & 2740 & 3707 & 5507 & $30-400$ \\
PT ratio & 1.23 & 1.32 & 2.19 & $0.84-1.2$ \\
aPTT ratio & 0.86 & 0.88 & 2.4 & $0.86-1.2$ \\
Fibrinogen (mg/dL) & 353 & 162 & 53 & $165-350$ \\
Triglycerides (mg/dL) & 293 & 286 & 396 & $<150$ \\
CRP (mg/dL) & 13.44 & 6.76 & 5.8 & $<0.5$ \\
\hline
\end{tabular}

$\overline{\mathrm{Hb}}$, hemoglobin; PLT, platelet count; WBC, white blood cells; LDH, lactate dehydrogenase; CRP, C reactive protein.

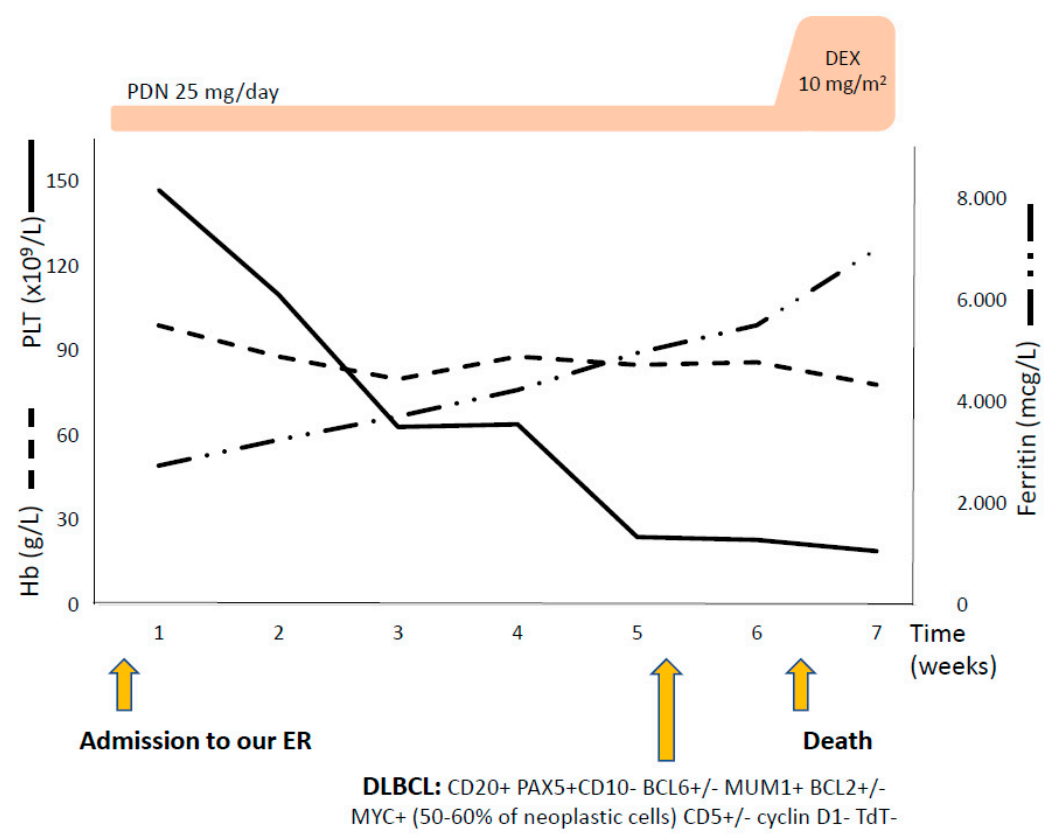

Figure 3. Clinical course of patient \#2. Trend of hematologic parameters and therapies administered. $\mathrm{Hb}$ : hemoglobin; PLT: platelet count; PDN: prednisone; DEX: dexamethasone; ER: emergency room; DLBCL: diffuse large B cell lymphoma with its immunophenotype.

\section{Review of the Literature}

\subsection{Secondary $H L H$}

Table 4 shows the several conditions that may induce secondary HLH. Infections are the most frequent underlying cause, accounting for a half of all HLH cases, with nearly $70 \%$ being secondary to viruses, mainly Herpes virus [11-23]. In a review of nearly 2200 cases of adult HLH and several case reports, infections are associated with a worse outcome in the presence of underlying immunodeficiency or cancer, and requirement of intensive care unit admission [11-23]. Consistently, hematological and solid cancers are the second most frequent cause of secondary HLH [12,16,19,20,24]. The main association is lymphoma, particularly T-cell and aggressive NHL, which also carry the highest mortality [2,12]. Infec- 
tions, particularly EBV and CMV, are the main precipitating factors in HLH secondary to NHL. Other hematologic conditions include Hodgkin lymphoma, Castleman disease, acute myeloid leukemia, and myelodysplastic syndromes $[12,16,20]$. Lastly, HLH is a rare complication of solid tumors too (pancreas, liver, pituitary cancer and neuroblastoma, etc.) [24] Less is known about the association of HLH with autoimmune diseases. Frequency is maximal for systemic lupus erythematosus (SLE, up to 6\%), followed by Still's disease, arthritis and inflammatory bowel diseases $[12,19,20,23,25]$. Interestingly, therapies impact on mortality, in that patients treated with high dose dexamethasone and etoposide display a mortality $>70 \%$, whilst those treated with targeted therapies (including tocilizumab, anakinra, rituximab etc.) had a mortality $<10 \%$ [12,19]. Regarding stem cell transplant (SCT), HLH is marked by increased percentage of macrophages and hemophagocytes in bone marrow aspirates and splenomegaly. HLH is associated with higher risk of engraftment failure and mortality $>80 \%$ at 2 years [26]. Case reports of HLH complicating solid transplants have also been described, mainly kidney and liver transplant (up to $6 \%$ ) $[12,19]$. HLH following primary immunodeficiencies are described in few case series, consistently with the rarity of both conditions. An infectious trigger is almost invariably present, particularly CMV and EBV, but even rare microbes such as Burkholderia cepacia and Leishmania, leading to a dismal outcome [12,19,27-29]. Finally, several drugs may be linked to secondary HLH, including targeted therapies (rituximab, infliximab, etanercept, BRAF/MEK inhibitor, nivolumab), anti-microbials, -tubercular and -retroviral agents, and other compounds (all trans retinoic acid, bucillamine, cyclophosphamide, diphenylhydantoin, diaminodiphenylsulfone, metamizole, sulfasalazine, thiopurine, zonisamide) $[12,23,30,31]$. Influenza and Bacillus Calmette-Guerin vaccinations have also been described as possible triggers of HLH [32,33].

\subsection{Secondary AIC}

Even AIC may be secondary to a variety of conditions, particularly infections and lymphoproliferative disorders (up to $20 \%$ for both), as recently reviewed elsewhere (Table 4) [34-36]. Regarding infections, the most common association is with parvovirus B19, followed by chronic viral hepatitis (particularly HCV) [37,38]. Moreover, mycoplasma pneumonia may induce cold agglutinin syndrome, and syphilis, EBV, and RSV infections may be responsible of paroxysmal cold hemoglobinuria in childhood [34,36]. Concerning cancers, the highest frequency of AIC is observed in chronic lymphocytic leukemia (CLL), with a relationship with disease progression and biologic risk $[39,40]$. Other hematologic conditions such as NHL, HL, and Castleman disease, and solid tumors including thymoma, ovarian and prostate cancer, may be more rarely complicated by AIC [34,36]. Other autoimmune conditions may be accompanied by AIC, including rheumatoid arthritis, thyroiditis, and SLE, where AIC are part of the diagnostic criteria [41-46]. AIC may also be associated with primary immunodeficiencies, such as IgA deficiency, common variable immunodeficiency and the autoimmune lymphoproliferative syndrome $[47,48]$. The latter are typical of childhood, where diagnosis is of particular importance in order to avoid excessive immunosuppression [36]. Regarding transplants, AIC may complicate SCT in up to $15 \%$ of cases and are often life threatening and multi-refractory [49-53]. Finally, many case reports describe the occurrence of AIC after exposure to various drugs including antibiotics, antifungal and anticancer drugs. Among the latter, it is worth reminding fludarabine and alemtuzumab, utilized in CLL, and checkpoint inhibitors (i.e., anti-PD1/PDL1 and anti-CTLA4) used in HL and solid cancers $[6,7,34,36,54]$. 
Table 4. Causes of secondary hemophagocytic lymphohystiocytosis (HLH) and autoimmune hemolytic anemia (AIHA).

\begin{tabular}{|c|c|c|c|}
\hline Secondary HLH & Frequency & Notes & Ref \\
\hline Infections & $<5 \%$ to $50 \%$ & $\begin{array}{l}\text { Virus (CMV, EBV, influenza, adenovirus, dengue, } \\
\text { SARS-CoV-2, HIV); bacteria (E. coli, mycoplasma, } \\
\text { mycobacterium, tick-borne bacteria); } \\
\text { fungi (histoplasma, aspergillus); } \\
\text { parasites (malaria, Leishmania) }\end{array}$ & [11-23] \\
\hline Cancers & $\begin{array}{l}10 \text { to } 47 \% \\
\quad 3 \%\end{array}$ & $\begin{array}{l}\text { Hematologic cancers, particularly lymphoma } \\
\text { Solid cancers, particularly thymoma, } \\
\text { ovarian and prostate cancer }\end{array}$ & {$[12,16,19,20,24]$} \\
\hline Autoimmune diseases & 10 to $40 \%$ & $\begin{array}{l}\text { Systemic lupus erythematosus; rheumatoid arthritis; } \\
\text { juvenile idiopathic arthritis; inflammatory bowel } \\
\text { syndromes; Still's disease; diabetes mellitus; } \\
\text { sarcoidosis; psoriasis; Kawasaki and Kikuchi diseases; } \\
\text { Steven-Johnson syndrome. }\end{array}$ & {$[12,19,20,23,25]$} \\
\hline Transplants & $\begin{array}{c}\text { Up to } 17 \% \\
\text { Case reports to } 6 \%\end{array}$ & $\begin{array}{l}\text { Stem cell transplants } \\
\text { Solid organ transplants }\end{array}$ & {$[12,19,26]$} \\
\hline Primary immunodeficiencies & Case series & $\begin{array}{l}\text { Severe combined immunodeficiency; DiGeorge } \\
\text { syndrome; Wiskott-Aldrich syndrome; chronic } \\
\text { granulomatous disease }\end{array}$ & {$[12,19,27-29]$} \\
\hline Drugs & Case reports & $\begin{array}{l}\text { Several drugs including targeted anti-cancer } \\
\text { immunosuppressants and anti-microbial drugs }\end{array}$ & {$[12,23,30,31]$} \\
\hline Vaccinations & Case reports & Influenza and Bacillus Calmette Guerin vaccinations & {$[32,33]$} \\
\hline Secondary AIHA & Frequency & Notes & Ref \\
\hline Infections & Case reports to $20 \%$ & $\begin{array}{l}\text { Parvovirus B19, HCV, HBV, HAV, HIV, Mycoplasma } \\
\text { spp, tuberculosis, babesiosis, brucellosis, syphilis, EBV, } \\
\text { respiratory syncytial virus }\end{array}$ & [34-38] \\
\hline Cancers & $<5 \%$ to $30 \%$ & $\begin{array}{l}\text { Solid tumors } \\
\text { Hematologic cancers }\end{array}$ & {$[34,36,39,40]$} \\
\hline Autoimmune diseases & 1 to $14 \%$ & $\begin{array}{c}\text { Systemic lupus erythematosus, systemic sclerosis, } \\
\text { autoimmune thyroiditis, Sjogren syndrome, } \\
\text { inflammatory bowel syndrome, autoimmune } \\
\text { hepatitis/primary biliary cirrhosis }\end{array}$ & [41-46] \\
\hline Primary immunodeficiencies & 2 to $>50 \%$ & $\begin{array}{l}\text { Autoimmune lymphoproliferative syndrome, common } \\
\text { variable immunodeficiency, IgA deficiency }\end{array}$ & {$[36,47,48]$} \\
\hline Transplants & 2 to $15 \%$ & Stem cell transplants and solid organ transplants & [49-53] \\
\hline Drugs and vaccines & Case reports & $\begin{array}{c}\text { Antibiotics, anti-fungal, antipsychotics, } \\
\text { anti-convulsive, anti-neoplastic, anti-diabetics, and } \\
\text { novel anti-cancers (Fludarabine, Bruton tyrosine kinase } \\
\text { inhibitor, phosphoinositide 3-kinase and } \\
\text { checkpoint inhibitors) }\end{array}$ & {$[6,7,34,36,54]$} \\
\hline
\end{tabular}

\section{Discussion}

Here we present two cases of fatal HLH and AIC with underlying DLBCL, whose diagnosis was challenged by an acute and atypical presentation. In particular, patient 1 showed a rapid evolution with fatal outcome in few days. The extremely elevated LDH levels and splenomegaly, both markers of NHL, could have raised the suspicion of a secondary AIHA. As a matter of fact, bone marrow evaluation in warm AIHA is recommended when a secondary form is suspected, in case of multiple cytopenias and reticulocytopenia, and in cases relapsed/refractory after first line steroid therapy [5,7]. Even in Case 2 the important splenomegaly and increased beta- 2 microglobulin levels could have suggested a lymphoproliferative disorder. However, the transient response to steroids, the lack of clear DAT positivity, and the subacute evolution of anemia delayed bone marrow evaluation and the subsequent diagnosis of DLBCL. Both cases developed thrombocytopenia, suggesting an Evans syndrome (association of AIHA and ITP), especially in Patient 2, who displayed anti-platelet autoantibodies. However, the latter test has low sensitivity and specificity and DAT may be negative in up to $10 \%$ of AIHA cases notwithstanding more 
sensitive methods [5-7]. In such cases, the differential diagnosis of hemolytic anemia may be difficult, requiring the exclusion of paroxysmal nocturnal hemoglobinuria, thrombotic microangiopathies, intravascular devices, congenital hemolytic disorders, and the very rare congenital dyserythropoietic anemias. Moreover, hemolytic markers reckon many confounders (nutrients deficiencies, inflammation, chronic liver diseases, etc.), and may also be altered in sepsis and HLH (Table 5) [55]. Finally, it is worth reminding that cases of "false" DAT positivity may also occur (i.e., about $1 \%$ of hospitalized patients) after administration of various medications (i.e., ivIg, daratumumab, anti- thymocyte globulin, etc.) and in the presence of alloantibodies in recently transfused patients [5-7].

Table 5. Markers of hemolysis in different settings including HLH and sepsis.

\begin{tabular}{|c|c|c|c|c|c|c|c|c|}
\hline & AIHA & $\begin{array}{c}\text { Membrane/ } \\
\text { Enzyme Defects }\end{array}$ & CDA & PNH & TMA & $\begin{array}{l}\text { Intravascular } \\
\text { Devices }\end{array}$ & HLH & SIRS/Sepsis \\
\hline $\mathrm{Hb}$ & - to --- & $-1--$ & $--1---$ & $--1---$ & $--1---$ & - & $=$ to --- & $=$ to - \\
\hline Reticulocytes & - to +++ & - to +++ & $-1=$ & - to ++ & + & + & - to + & - \\
\hline Schistocytes & $=$ & $=$ & $=$ & $=$ & ++ & + & $=$ & $=$ \\
\hline $\mathrm{LDH}$ & $+/++$ & + & + & +++ & ++ & ++ & + to +++ & $=$ to + \\
\hline Haptoglobin & --- & --- & -- & --- & - & -- & $=$ to + & $+/++$ \\
\hline Bilirubin & + & ++ & + & + & + & + & $=$ to + & $=$ \\
\hline Ferritin & $=/+$ & ++ & +++ & - to + & $=/+$ & $=/+$ & +++ & $+/++$ \\
\hline PLT & $=/--$ & $=/-$ & $=$ & $=/-$ & -- & $=/-$ & $=$ to --- & + \\
\hline WBC & $=$ & $=$ & $=$ & $=/-$ & $=$ & $=/-$ & $=$ to --- & - to ++ \\
\hline Hemosiderinuria & $=/+$ & $=$ & $=$ & + to +++ & $=/+$ & $=/+$ & $=$ & $=$ \\
\hline
\end{tabular}

Values are expressed in a semiquantitative style to indicate the different intensity of alteration in the various hemolytic syndromes, as follows: $+/++/+++$ indicate an increase from mild to severe, $-/--/---$ indicate a reduction, and $=$ indicates values within the normal range (updated by Barcellini $\mathrm{W}$ et al. [55]). AIHA, autoimmune hemolytic anemia; CDA, congenital dyserythropoietic anemia; PNH, paroxysmal nocturnal hemoglobinuria; TMA, thrombotic microangiopathy; HLH, hemophagocytic lymphohystiocytosis; SIRS, systemic inflammatory response syndrome; $\mathrm{Hb}$, hemoglobin; $\mathrm{LDH}$, lactate dehydrogenase; PLT, platelets; WBC, white blood cells.

Even HLH may be secondary to several conditions common to AIC. Its diagnosis is frequently difficult because of the acute and severe setting, and since criteria lack specificity. In particular, HLH-2004 criteria have been proposed for primary forms and validated in the pediatric population only. However, various case series have used modified HLH-2004 criteria in adults [56-58] and represent the diagnostic tool suggested by the American Society of Hematology guidelines [3]. Moreover, the HLH-probability calculator (HScore), specifically designed for adults, may be useful since it encompasses graded clinical and laboratory parameters, and additional criteria compared to HLH2004 [1]. In the described cases, HScores were 266 and 239, respectively, reaching the diagnostic threshold [1]. Finally, increased levels of serum soluble interleukin-2 receptor (sIL-2r), included in the HLH2004 criteria, have been recently indicated as a specific marker of malignancy-associated HLH in adults [59]. In any case, the proposed cutoffs have been empirically defined, and some tests, particularly sIL-2r, are not routinely available [1-4]. In addition, patients not fulfilling all criteria at the time of evaluation should not be disregarded, since they may subsequently develop overt disease $[1-3,9,10]$. In the described cases, features suggestive for HLH developed subacutely and were confounded by the presence of AIC and sepsis. A peculiar setting is that of ICU, where a recent study investigating $40 \mathrm{HLH}$ patients out of 2623 displaying hyperferritinemia indicated that ferritin $>3000 \mathrm{mcg} / \mathrm{L}$ and an HScore cutoff of 168 were the most sensitive and specific criteria [60].

Importantly, clinical presentation may have been attenuated by concomitant steroid therapy given for AIC. The latter may be a double-edged sword, since it is useful both in AIC and HLH, but inadequate dose may be ineffective and, rather, confound the clinical picture. As a matter of fact, treatment of acquired HLH in adults is not agreed on: the scaffold relies on HLH94 protocol including high dose dexamethasone, etoposide, and cyclosporine A [9]. Of note it is important to aggressively treat the underlying condition with additional specific therapies: chemotherapy for malignancies, rituximab for EBV-associated HLH, IVIG and antimicrobials for infections, anti-interleukin 1 for HLH associated with autoimmune diseases, and anti-interleukin 6 in HLH secondary to immune checkpoint inhibitors/chimeric antigen T cells $[3,61]$. 
In conclusion, the differential diagnosis of cytopenias in the internal medicine setting can be particularly challenging since the onset can be acute and life-threatening. The "diagnostic funnel" requires the knowledge and suspicion of both common and rare conditions, including AIC and HLH. Both may be fatal and should prompt the exclusion of underlying diseases, such as aggressive lymphomas. Finally, immediate immune suppressive treatment is necessary to avoid fatal multiple organ dysfunction syndrome.

Author Contributions: Conceptualization, B.F., M.F., J.A.G. and W.B.; data curation, B.F., M.F., J.A.G. and W.B.; writing — original draft, B.F., M.F., J.A.G. and W.B.; writing—review and editing, B.F., M.F., J.A.G. and W.B. All authors have read and agreed to the published version of the manuscript.

Funding: This research received no external funding.

Institutional Review Board Statement: The study was conducted in accordance with the Helsinki declaration.

Informed Consent Statement: Informed consent was obtained from all subjects involved in the study.

Data Availability Statement: The data presented in this study are available on request from the corresponding author. The data are not publicly available due to privacy reasons.

Conflicts of Interest: All authors declare no conflicts of interest.

\section{References}

1. Fardet, L.; Galicier, L.; Lambotte, O.; Marzac, C.; Aumont, C.; Chahwan, D.; Coppo, P.; Hejblum, G. Development and validation of the HScore, a score for the diagnosis of reactive hemophagocytic syndrome. Arthritis Rheumatol. 2014, 66, 2613-2620. [CrossRef]

2. Larroche, C. Hemophagocytic lymphohistiocytosis in adults: Diagnosis and treatment. Jt. Bone Spine 2012, 79, 356-361. [CrossRef]

3. La Rosée, P.; Horne, A.; Hines, M.; Greenwood, T.B.; Machowicz, R.; Berliner, N.; Birndt, S.; Gil-Herrera, J.; Girschikofsky, M.; Jordan, M.B.; et al. Recommendations for the management of hemophagocytic lymphohistiocytosis in adults. Blood 2019, 133, $2465-2477$.

4. Janka, G.E.; Lehmberg, K. Hemophagocytic syndromes-An update. Blood Rev. 2014, 28, 135-142. [CrossRef] [PubMed]

5. Jäger, U.; Barcellini, W.; Broome, C.M.; Gertz, M.A.; Hill, A.; Hill, Q.A.; Jilma, B.; Kuter, D.J;; Michel, M.; Montillo, M.; et al. Diagnosis and treatment of autoimmune hemolytic anemia in adults: Recommendations from the First International Consensus Meeting. Blood Rev. 2020, 41, 100648. [CrossRef] [PubMed]

6. Barcellini, W.; Fattizzo, B. The Changing Landscape of Autoimmune Hemolytic Anemia. Front. Immunol. 2020, 11, 946. [CrossRef] [PubMed]

7. Fattizzo, B.; Giannotta, J.A.; Serpenti, F.; Barcellini, W. Difficult Cases of Autoimmune Hemolytic Anemia: A Challenge for the Internal Medicine Specialist. J. Clin. Med. 2020, 9, 3858. [CrossRef] [PubMed]

8. Henter, J.I.; Horne, A.; Aricó, M.; Egeler, R.M.; Filipovich, A.H.; Imashuku, S.; Ladisch, S.; McClain, K.; Webb, D.; Winiarski, J.; et al. HLH-2004: Diagnostic and therapeutic guidelines for hemophagocytic lymphohistiocytosis. Pediatric Blood Cancer 2007, 48, 124-131. [CrossRef] [PubMed]

9. Ramachandran, S.; Zaidi, F.; Aggarwal, A.; Gera, R. Recent advances in diagnostic and therapeutic guidelines for primary and secondary hemophagocytic lymphohistiocytosis. Blood Cells Mol. Dis. 2017, 64, 53-57. [CrossRef]

10. Machowicz, R.; Janka, G.; Wiktor-Jedrzejczak, W. Similar but not the same: Differential diagnosis of HLH and sepsis. Crit. Rev. Oncol. Hematol. 2017, 114, 1-12. [CrossRef]

11. Martín, A.; Marques, L.; Soler-Palacín, P.; Caragol, I.; Hernandez, M.; Figueras, C.; Español, T. Visceral leishmaniasis associated hemophagocytic syndrome in patients with chronic granulomatous disease. Pediatric Infect. Dis. J. 2009, 28, 753-754. [CrossRef] [PubMed]

12. Ramos-Casals, M.; Brito-Zerón, P.; López-Guillermo, A.; Khamashta, M.A.; Bosch, X. Adult haemophagocytic syndrome. Lancet 2014, 383, 1503-1516. [CrossRef]

13. Singh, P.K.; Kodati, R.; Rohilla, M.; Sharma, P. Hemophagocytic lymphohistiocytosis: A rare association with pulmonary cryptococcosis. BMJ Case Rep. 2019, 12, e230255. [CrossRef] [PubMed]

14. Agrawal, G.; Wazir, S.; Sachdeva, A.; Kumar, S. Primary dengue infection triggered haemophagocytic lymphohistiocytosis in a neonate. BMJ Case Rep. 2020, 13, e236881. [CrossRef] [PubMed]

15. Retamozo, S.; Brito-Zerón, P.; Sisó-Almirall, A.; Flores-Chávez, A.; Soto-Cárdenas, M.J.; Ramos-Casals, M. Haemophagocytic syndrome and COVID-19. Clin. Rheumatol. 2021, 3, 1-12.

16. Siddiqui, R.S.; Agladze, M.; Bashir, T. Hemophagocytic Lymphohistiocytosis as the Presenting Manifestation of Relapsed Classic Hodgkin's Lymphoma in the Presence of Concurrent Human Immunodeficiency Virus, Genital Herpes, Epstein-Barr Virus and Mycobacterium Avium Complex Infection. Cureus 2020, 12, e11563. [CrossRef] [PubMed]

17. Valentine, G.; Thomas, T.A.; Nguyen, T.; Lai, Y.C. Chronic granulomatous disease presenting as hemophagocytic lymphohistiocytosis: A case report. Pediatrics 2014, 134, e1727-e1730. [CrossRef] [PubMed] 
18. Srivatsav, S.; Mahalingam, S.; Ramineni, P.; Manya, S. Dengue and Plasmodium falciparum Coinfection with Secondary Hemophagocytic Lymphohistiocytosis in a 3-Year-Old Boy: A Clinical Conundrum. J. Pediatric Hematol. Oncol. 2020. [CrossRef]

19. Posas-Mendoza, T.F.; McLeod, C.; Davis, W.; Zakem, J.; Quinet, R. Etiologies and management of haemophagocytic lymphohistiocytosis: Is it time for an updated protocol and targeted treatments? Rheumatology 2020. [CrossRef] [PubMed]

20. Kwak, A.; Jung, N.; Shim, Y.J.; Kim, H.S.; Lim, H.J.; Lee, J.M.; Heo, M.H.; Do, Y.R. A retrospective analysis of etiology and outcomes of hemophagocytic lymphohistiocytosis in children and adults. Yeungnam Univ. J. Med. 2020. [CrossRef]

21. Sağlam, B.; Albayrak, M.; Acar, A.; Yıldız, A.; Maral, S.; Tığlığlu, M.; Battal, İ.; Şahin, E.N.; Kuş, A. Q fever as a rare cause of hemophagocytic lymphohistiocytosis: Case report. Transfus. Apher. Sci. 2020, 59, 102747. [CrossRef]

22. Von Bahr Greenwood, T.; Holzgraefe, B.; Chiang, S.C.C.; Wang, Y.; Tesi, B.; Bryceson, Y.T.; Henter, J.I. Clinical and laboratory signs of haemophagocytic lymphohistiocytosis associated with pandemic influenza A (H1N1) infection in patients needing extracorporeal membrane oxygenation: A retrospective observational study. Eur. J. Anaesthesiol. 2020. [CrossRef]

23. Soy, M.; Atagündüz, P.; Atagündüz, I.; Sucak, G.T. Hemophagocytic lymphohistiocytosis: A review inspired by the COVID-19 pandemic. Rheumatol. Int. 2021, 41, 7-18. [CrossRef] [PubMed]

24. Nascimento, F.A.; Nery, J.; Trennepohl, J.; Pianovski, M.A. Hemophagocytic Lymphohistiocytosis after Initiation of Chemotherapy for Bilateral Adrenal Neuroblastoma. J. Pediatric Hematol. Oncol. 2016, 38, e13-e15. [CrossRef]

25. Kuruvilla, N.; Rajendran, R.; Thomas, S.S.; Ali Km, I.; Kurian, S. An Unusual Presentation of Adult-Onset Still's Disease as Hemophagocytic Lymphohistiocytosis in a Male Patient. Cureus 2020, 12, e11139. [CrossRef] [PubMed]

26. Hattori, N.; Sato, M.; Uesugi, Y.; Nakata, A.; Sasaki, Y.; Shimada, S.; Watanuki, M.; Fujiwara, S.; Kawaguchi, Y.; Arai, N.; et al. Characteristics and predictors of post-transplant-associated hemophagocytic lymphohistiocytosis in adults. Int. J. Hematol. 2021. [CrossRef]

27. Faitelson, Y.; Grunebaum, E. Hemophagocytic lymphohistiocytosis and primary immune deficiency disorders. Clin. Immunol. 2014, 155, 118-125. [CrossRef] [PubMed]

28. Bode, S.F.; Ammann, S.; Al-Herz, W.; Bataneant, M.; Dvorak, C.C.; Gehring, S.; Gennery, A.; Gilmour, K.C.; Gonzalez-Granado, L.I.; Groß-Wieltsch, U.; et al. Inborn Errors Working Party of the EBMT. The syndrome of hemophagocytic lymphohistiocytosis in primary immunodeficiencies: Implications for differential diagnosis and pathogenesis. Haematologica 2015, 100, 978-988. [CrossRef]

29. Squire, J.D.; Vazquez, S.N.; Chan, A.; Smith, M.E.; Chellapandian, D.; Vose, L.; Teppa, B.; Hanson, I.C.; Chinn, I.K.; Forbes-Satter, L.; et al. Case Report: Secondary Hemophagocytic Lymphohistiocytosis with Disseminated Infection in Chronic Granulomatous Disease-A Serious Cause of Mortality. Front. Immunol. 2020, 11, 581475. [CrossRef] [PubMed]

30. Vick, E.J.; Patel, K.; Prouet, P.; Martin, M.G. Proliferation through activation: Hemophagocytic lymphohistiocytosis in hematologic malignancy. Blood Adv. 2017, 1, 779-791. [CrossRef] [PubMed]

31. Dudda, M.; Mann, C.; Heinz, J.; Schmidgen, I.; Weid, F.; Kühn, M.; Saloga, J.; Grabbe, S.; Loquai, C. Hemophagocytic lymphohistiocytosis of a melanoma patient under BRAF/MEK-inhibitor therapy following anti-PD1 inhibitor treatment: A case report and review to the literature. Melanoma Res. 2021, 31, 81-84. [CrossRef] [PubMed]

32. Ikebe, T.; Takata, H.; Sasaki, H.; Miyazaki, Y.; Ohtsuka, E.; Saburi, Y.; Ogata, M.; Shirao, K. Hemophagocytic lymphohistiocytosis following influenza vaccination in a patient with aplastic anemia undergoing allogeneic bone marrow stem cell transplantation. Int. J. Hematol. 2017, 105, 389-391. [CrossRef] [PubMed]

33. González, M.J.; Franco, A.G.; Alvaro, C.G. Hemophagocytic lymphohistiocytosis secondary to Calmette-Guèrin bacilli infection. Eur. J. Intern. Med. 2008, 19, 150. [CrossRef] [PubMed]

34. Hill, Q.A.; Stamps, R.; Massey, E.; Grainger, J.D.; Provan, D.; Hill, A.; British Society for Haematology Guidelines. Guidelines on the management of drug-induced immune and secondary autoimmune, hemolytic anaemia. Br. J. Haematol. 2017, 177, 208-220. [CrossRef] [PubMed]

35. Giannotta, J.A.; Fattizzo, B.; Cavallaro, F.; Barcellini, W. Infectious Complications in Autoimmune Hemolytic Anemia. J. Clin. Med. 2021, 10, 164. [CrossRef] [PubMed]

36. Barcellini, W.; Giannotta, J.; Fattizzo, B. Autoimmune hemolytic anemia in adults: Primary risk factors and diagnostic procedures. Expert Rev. Hematol. 2020, 13, 585-597. [CrossRef]

37. El Khoury, C.; Farhat, H. Severe acute anemia attributable to concomitant occurrence of AIHA with PRCA induced by parvovirus B19 infection. Blood 2018, 131, 1388. [CrossRef]

38. Chiao, E.Y.; Engels, E.A.; Kramer, J.R.; Pietz, K.; Henderson, L.; Giordano, T.P.; Landgren, O. Risk of immune thrombocytopenic purpura and autoimmune hemolytic anemia among 120908 US veterans with hepatitis C virus infection. Arch. Intern. Med. 2009, 169, 357-363. [CrossRef]

39. Visco, C.; Barcellini, W.; Maura, F.; Neri, A.; Cortelezzi, A.; Rodeghiero, F. Autoimmune cytopenias in chronic lymphocytic leukemia. Am. J. Hematol. 2014, 89, 1055-1062. [CrossRef]

40. Fattizzo, B.; Barcellini, W. Autoimmune Cytopenias in Chronic Lymphocytic Leukemia: Focus on Molecular Aspects. Front. Oncol. 2020, 9, 1435. [CrossRef]

41. Gormezano, N.W.; Kern, D.; Pereira, O.L.; Esteves, G.C.; Sallum, A.M.; Aikawa, N.E.; Pereira, R.M.; Silva, C.A.; Bonfá, E. Autoimmune hemolytic anemia in systemic lupus erythematosus at diagnosis: Differences between pediatric and adult patients. Lupus 2017, 26, 426-430. [CrossRef] [PubMed] 
42. Katsumata, K. A case of systemic sclerosis complicated by autoimmune hemolytic anemia. Mod. Rheumatol. 2006, 16, 191-195. [CrossRef] [PubMed]

43. Oh, H.J.; Yun, M.J.; Lee, S.T.; Lee, S.J.; Oh, S.Y.; Sohn, I. Evans syndrome following long-standing Hashimoto's thyroiditis and successful treatment with rituximab. Korean J. Hematol. 2011, 46, 279-282. [CrossRef]

44. Moore, J.A.; Gliga, L.; Nagalla, S. Thyroid storm and warm autoimmune hemolytic anemia. Transfus. Apher. Sci. 2017, 56, 606-608. [CrossRef] [PubMed]

45. Hegazi, M.O.; Ahmed, S. Atypical clinical manifestations of graves' disease: An analysis in depth. J. Thyroid Res. 2012, 2012, 768019. [CrossRef] [PubMed]

46. Efe, C.; Wahlin, S.; Ozaslan, E.; Berlot, A.H.; Purnak, T.; Muratori, L.; Quarneti, C.; Yüksel, O.; Thiéfin, G.; Muratori, P. Autoimmune hepatitis/primary biliary cirrhosis overlap syndrome and associated extrahepatic autoimmune diseases. Eur. J. Gastroenterol. Hepatol. 2012, 24, 531-534. [CrossRef] [PubMed]

47. Oliveira, J.B. The expanding spectrum of the autoimmune lymphoproliferative syndromes. Curr. Opin. Pediatrics 2013, 25, 722-729. [CrossRef]

48. Feuille, E.J.; Anooshiravani, N.; Sullivan, K.E.; Fuleihan, R.L.; Cunningham-Rundles, C. Autoimmune Cytopenias and Associated Conditions in CVID: A Report from the USIDNET Registry. J. Clin. Immunol. 2018, 38, 28-34. [CrossRef] [PubMed]

49. Li, M.; Goldfinger, D.; Yuan, S. Autoimmune hemolytic anemia in pediatric liver or combined liver and small bowel transplant patients: A case series and review of the literature. Transfusion 2012, 52, 48-54. [CrossRef]

50. González-Vicent, M.; Sanz, J.; Fuster, J.L.; Cid, J.; de Heredia, C.D.; Morillo, D.; Fernández, J.M.; Pascual, A.; Badell, I.; Serrano, D.; et al. Autoimmune hemolytic anemia (AIHA) following allogeneic hematopoietic stem cell transplantation (HSCT): A retrospective analysis and a proposal of treatment on behalf of the Grupo Español De Trasplante de Medula Osea en Niños (GETMON) and the Grupo Español de Trasplante Hematopoyetico (GETH). Transfus. Med. Rev. 2018, 3, S0887-S7963.

51. Kruizinga, M.D.; van Tol, M.J.D.; Bekker, V.; Netelenbos, T.; Smiers, F.J.; Bresters, D.; Jansen-Hoogendijk, A.M.; van Ostaijen-Ten Dam, M.M.; Kollen, W.J.W.; Zwaginga, J.J.; et al. Risk Factors, Treatment, and Immune Dysregulation in Autoimmune Cytopenia after Allogeneic Hematopoietic Stem Cell Transplantation in Pediatric Patients. Biol. Blood Marrow Transplant. 2018, $24,772-778$. [CrossRef]

52. Skeate, R.; Singh, C.; Cooley, S.; Geller, M.; Northouse, J.; Welbig, J.; Slungaard, A.; Miller, J.; McKenna, D. Hemolytic anemia due to passenger lymphocyte syndrome in solid malignancy patients treated with allogeneic natural killer cell products. Transfusion 2013, 53, 419-423. [CrossRef]

53. Barcellini, W.; Fattizzo, B.; Zaninoni, A. Management of refractory autoimmune hemolytic anemia after allogeneic hematopoietic stem cell transplantation: Current perspectives. J. Blood Med. 2019, 10, 265-278. [CrossRef]

54. Klein, N.P.; Ray, P.; Carpenter, D.; Hansen, J.; Lewis, E.; Fireman, B.; Black, S.; Galindo, C.; Schmidt, J.; Baxter, R. Rates of autoimmune diseases in Kaiser Permanente for use in vaccine adverse event safety studies. Vaccine 2010, 28, 1062-1068. [CrossRef]

55. Barcellini, W.; Fattizzo, B. Clinical Applications of Hemolytic Markers in the Differential Diagnosis and Management of Hemolytic Anemia. Dis. Markers 2015, 2015, 635670. [CrossRef]

56. Rivière, S.; Galicier, L.; Coppo, P.; Marzac, C.; Aumont, C.; Lambotte, O.; Fardet, L. Reactive hemophagocytic syndrome in adults: A retrospective analysis of 162 patients. Am. J. Med. 2014, 127, 1118-1125. [CrossRef] [PubMed]

57. Schram, A.M.; Comstock, P.; Campo, M.; Gorovets, D.; Mullally, A.; Bodio, K.; Arnason, J.; Berliner, N. Haemophagocytic lymphohistiocytosis in adults: A multicentre case series over 7 years. Br. J. Haematol. 2016, 172, 412-419. [CrossRef]

58. Arca, M.; Fardet, L.; Galicier, L.; Rivière, S.; Marzac, C.; Aumont, C.; Lambotte, O.; Coppo, P. Prognostic factors of early death in a cohort of 162 adult haemophagocytic syndrome: Impact of triggering disease and early treatment with etoposide. Br. J. Haematol. 2015, 168, 63-68. [CrossRef] [PubMed]

59. Hayden, A.; Lin, M.; Park, S.; Pudek, M.; Schneider, M.; Jordan, M.B.; Mattman, A.; Chen, L.Y.C. Soluble interleukin-2 receptor is a sensitive diagnostic test in adult HLH. Blood Adv. 2017, 1, 2529-2534. [CrossRef] [PubMed]

60. Knaak, C.; Nyvlt, P.; Schuster, F.S.; Spies, C.; Heeren, P.; Schenk, T.; Balzer, F.; La Rosée, P.; Janka, G.; Brunkhorst, F.M.; et al. Hemophagocytic lymphohistiocytosis in critically ill patients: Diagnostic reliability of HLH-2004 criteria and HScore. Crit. Care 2020, 24, 244. [CrossRef]

61. Shakoory, B.; Carcillo, J.A.; Chatham, W.W.; Amdur, R.L.; Zhao, H.; Dinarello, C.A.; Cron, R.Q.; Opal, S.M. Interleukin-1 Receptor Blockade Is Associated With Reduced Mortality in Sepsis Patients with Features of Macrophage Activation Syndrome: Reanalysis of a Prior Phase III Trial. Crit Care Med. 2016, 44, 275-281. [CrossRef] [PubMed] 